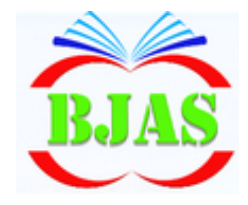

ISSN $1814-5868$
Available online at http://bajas.edu.iq

https://doi.org/10.37077/25200860.2021.34.1.02

College of Agriculture, University of Basrah

Basrah J. Agric. Sci., 34(1): 14-27, 2021

\section{Basrah Journal of Agricultural Sciences}

E-ISSN: 2520-0860

\title{
Energy Prediction of Wheat Production Using Data Mining Technique in Iran
}

\author{
Nasim Monjezi \\ Department of Biosystems Engineering, Faculty of Agriculture, Shahid Chamran \\ University of Ahvaz, Ahvaz, Iran \\ Corresponding author-mail: n.monjezi@scu.ac.ir \\ Received 27 September 2020; Accepted 18 December 2020; Available online 5 February 2021
}

\begin{abstract}
Wheat is considered as one of the most important products in Iran. Concerning high cultivation area of wheat in Khuzestan, an instrument is required to process stored data in order to give information resulted from such processing to managers of agricultural sectors. Data mining technique is able to give essential information and models to producers of wheat for modelling energy consumption. One of the most practical algorithms is an artificial neural network. The main aim of this research is to predict output energy of wheat farms using a multilayer perceptron neural network. This is an analytic research and its database consists of 1240 records. Data required for the research was obtained from wheat farm during 2014-2018. Data analysis was done via IBM SPSS modeller 14.2 and standard CRISP. Concerning the model used in the research, it was found that variables of chemical fertilizers, machinery \& diesel fuel with coefficients of $0.2987,0.2064$ and 0.1527 respectively had the highest effect on output variable (productive energy). Amount of prediction precision in neural network algorithm, meaning ratio of correctly predicted records to total records was $93.08 \%$. Also, linear correlation between actual values and predicted values were 0.92 and 0.88 respectively, for training data and testing data suggesting strong correlation. The results obtained can be effective for wheat farmers in direction of evaluation and optimization of energy consumption in process of wheat production and reduction of consumption of energy inputs.
\end{abstract}

Keywords: Energy, Predict, Data mining, ANN, Wheat.

\section{Introduction}

One of factors that cause stable production of agricultural products is optimal energy consumption. In one hand, concerning increasing price of agricultural inputs, paying more attention to optimal management of energy consumption is very important. Wheat is not exceptional as well. Energy in process of wheat production has been always paid attention due to its importance in decision making on application of different inputs. Therefore, optimization and modeling of energy consumption are very important in production of agricultural products, especially wheat. On the other hand, collected data are various with complex relationship and it is difficult to analyze and manage them via empirical and statistical analyses and experiences. Data mining is a powerful technology in management and organization of 
a large size of information. Data mining means searching in one database for finding inter-data patterns. Several researches have been conducted on application of data mining techniques in agriculture. Ferraro et al. (2009) analyze large production database describing crop yield patterns. They studied the influence of several factors controlling sugarcane productivity in one of the most important area of cane production in Argentina. They propose using a data mining technique called classification and regression tree to identify the dependence of sugarcane yield on the variation of both environmental and management factors. This paper provides useful information regarding Genotype $\times$ Environment interaction as it was possible to detect multiple paths for defining different sugarcane yield groups of crop fields using genotype, management and environmental variables.

Ekasingh et al. (2005) used the C4.5 data mining algorithm to model farmers' crop choice in two watersheds in Thailand. Result showed that the decision trees produced in this study could be useful to analyze of water resource management as they can be integrated with biophysical models for sustainable watershed management. Ramesh \& Vardhan (2013) predicted agricultural products yield using different data mining techniques such as k-means, k-nearest Neighbor, support vector machines and artificial neural network. They wanted to find a model with high accuracy and ability for prediction of yield of agricultural products.

Jeysenthil et al. (2014) designed and predicted a support system for database of soil using data mining clustering technique (kmeans). Everinghama et al. (2009) in Australia and Fernandes et al. (2011) in Brazil have estimated the yield of farms using data mining techniques. Goktepe et al. (2005) classified soils of Antalya region in 2005 using 120 soil samples via k-means and fuzzy clustering. Results of the research showed that fuzzy clustering method had more optimal result.

Medar \& Rajpurohit (2014) present the various crop yield prediction methods using data mining techniques. Different Data Mining techniques such as K-Means, K-Nearest Neighbor (KNN), Artificial Neural Networks (ANN) and Support Vector Machines (SVM) for very recent applications of data mining techniques in agriculture field. Mucherino et al. (2009) present some of the most used data mining techniques in the field of agriculture.

Some of these techniques, such as the kmeans, the $\mathrm{k}$ nearest neighbor, artificial neural networks and support vector machines, are discussed and an application in agriculture for each of these techniques is presented. In addition, the references included in brackets confirmed the ability and necessity of using data mining technique in agriculture (Raorane \& Kulkarni, 2013; Kalpana et al., 2014; Geetha, 2015; Khedr et al., 2015; Raorane \& Kulkarni, 2015; Almaliki et al., 2016; Almaliki, 2017; Oliveira et al., 2017; Thomas, 2017). Therefore, the energy used in wheat production was predicted and modelled using data mining techniques (Artificial Neural Network).

\section{Materials \& methods}

\section{The study site}

The present research was conducted on wheat farms of Khuzestan province in Iran. Using data in 2014-2018. Khuzestan province with an area $64055 \mathrm{~km}^{2}$ is located in southwest of Iran (within $29^{\circ} 58^{\prime}$ and $33^{\circ} 04^{\prime} \mathrm{N}$ and $47^{\circ} 41^{\prime}$ and $50^{\circ} 39^{\prime} \mathrm{E}$ ). Fig. (1) showed the position of Khuzestan province in Iran. 


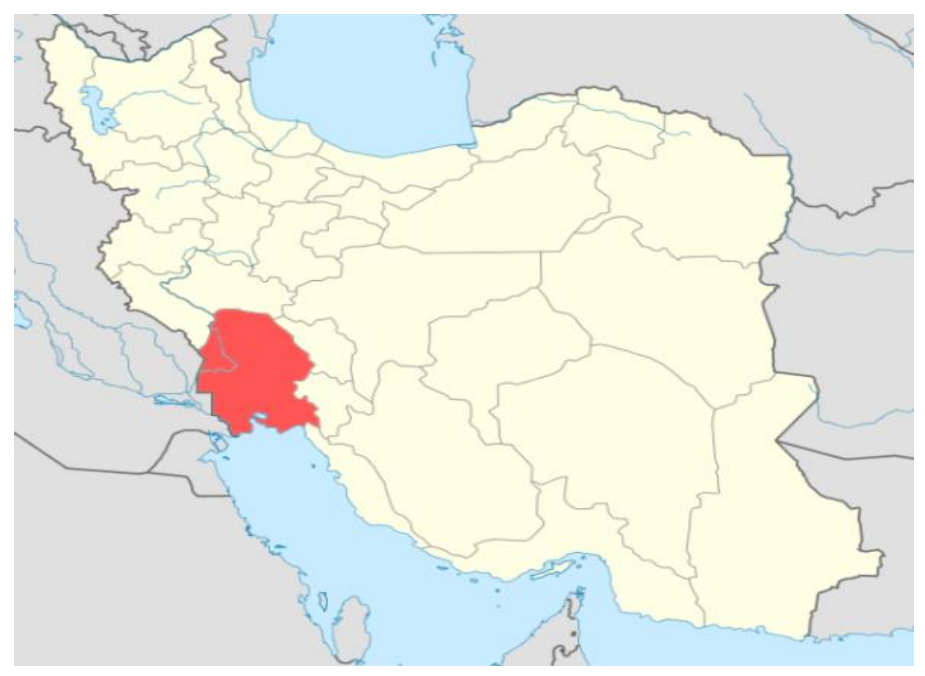

Fig. (1): The position of Khuzestan province in Iran.

\section{Energy equivalents of inputs and output}

The data included the quantity of various energy inputs used per hectare of wheat production, including: human labor, machinery, diesel fuel, chemicals, fertilizer, water for irrigation and electricity and seed, and the production yield as output. In order to analyze the energy of farmers, all of inputs and output were then converted into energy equivalents by multiplying the quantity of input use with their corresponding energy equivalent coefficients. The energy coefficients of inputs are the energy used from primary production to the end user. The energy equivalents of inputs were presented in table (1). The energy equivalent of human labor is the muscle power used in field operations of crop production. Chemicals and chemical fertilizers energy equivalents means the energy consumption for producing, packing and distributing the materials and they are given on an active ingredient basis. Also, the energy sequestered in diesel fuel and electricity means their heating value (enthalpy) and the energy needed to make their energy available directly to the farmers (Mousavi-Avval et al., 2011).

The energy equivalent of water for irrigation input means indirect energy of irrigation consist of the energy consumed for manufacturing the materials for the dams, canals, pipes, pumps, and equipment as well as the energy for constructing the works and building the on-farm irrigation systems (Khan et al., 2008). For calculating the embodied energy in agricultural machinery it was assumed that the energy consumed in the production of the tractors and agricultural machinery be depreciated during their economic life time (Beheshti Tabar et al., 2010); therefore, the machinery energy input was calculated using the following Eq. (Srivastava et al., 1993):

$$
E_{m}=\frac{E I_{m} \cdot W . T}{N}
$$

Where $E_{m}$ is the machinery energy per unit area $\left(\mathrm{MJ} \mathrm{ha}^{-1}\right)$; $\mathrm{W}$ is the machine mass $(\mathrm{kg})$; $\mathrm{EI}_{\mathrm{m}}$ the production energy of machine ( $\mathrm{MJ} \mathrm{kg}^{-}$ ${ }^{1}$ ); $\mathrm{T}$ is the time that machine used per unit 
Table (1). Energy coefficient equivalents of inputs and outputs.

\begin{tabular}{lccr}
\hline \multicolumn{1}{c}{ Inputs/outputs } & Unit & $\begin{array}{c}\text { Energy coefficient } \\
\text { equivalent (MJ unit-1) }\end{array}$ & \multicolumn{1}{c}{ Reference } \\
\hline Diesel Fuel & $\mathrm{L}$ & 47.8 & (Banaeian \& Zangeneh, 2011) \\
\hline Human Labor & $\mathrm{h}$ & 1.96 & (Mandal et al. 2002) \\
\hline Chemical Fertilizers & & & (Kaltschmitt et al. 1997) \\
\hline Nitrogen $(\mathrm{N})$ & $\mathrm{kg}$ & 47.1 & (Kaltschmitt et al. 1997) \\
\hline Phosphate $\left(\mathrm{P}_{2} \mathrm{O}_{5}\right)$ & $\mathrm{kg}$ & 15.8 & (Kaltschmitt et al. 1997) \\
\hline Chemical herbicide & $\mathrm{kg}$ & 238 & (Khoshnevisan et al. 2013) \\
\hline Machinery & $\mathrm{Kg} \mathrm{per} \mathrm{year}$ & 9 & (Mandal et al., 2002) \\
\hline seed & $\mathrm{kg}$ & 14.7 & (Kitani, 1999) \\
\hline Electricity & $\mathrm{kWh}$ & 11.93 &
\end{tabular}

area $\left(\mathrm{h} \mathrm{ha}^{-1}\right)$ and $\mathrm{N}$ is the economic life time of machine (h).

\section{Data mining technique}

Generally, data mining technique is divided into predictive and descriptive techniques (Fig. $2)$. The neural network is one of the most practical data mining techniques in prediction.

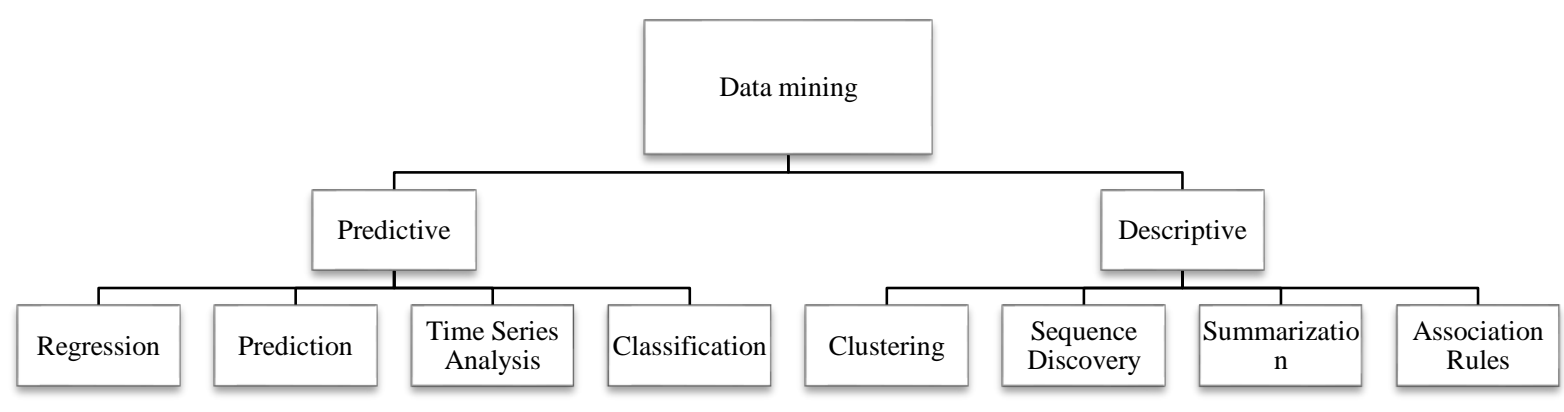

Fig. (2): Data mining techniques (Sharma 2006; Ayman et al. 2015)

\section{Artificial neural networks}

Neural networks can estimate approximately any continuous correlation between input and target even if such relationship is non-linear (Phillips-Wren et al. 2008). The most important feature of neural networks that is important in their application is their ability in learning samples (Efendigil et al. 2009). Learning method can be in three forms: with or without observer and both of them. Learning method with observer is conducted by pairs of input-output patterns while learning without observer includes offering training samples to the network and it continues until the highest separation is obtained among classes of samples. The most famous neural networks are multilayer perceptron neural networks that are trained with observer or error-back propagation algorithm (Liao \& Wen, 2007).

\section{Standard CRISP-DM}

This is a data-oriented research. Its main basis is to discover knowledge from database of wheat farms of Khuzestan province in Iran. Therefore, cross- industry standard process for 
data mining (CRISP-DM) was used in the research. This method presents a process model for data mining that reviews life cycle of each data mining project. Life cycle of each data mining project includes six stages of problem perception, data perception, data preparation, modelling, result evaluation and application of the model. Fig. (3) shows stages of this standard in the form of a process.

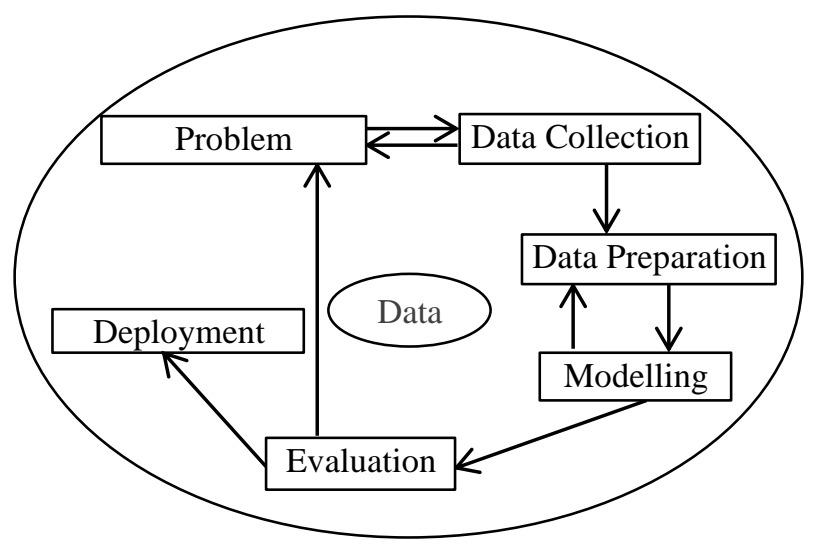

Fig. (3): Data mining process model (Chapman et al., 2011).

\section{Data analysis}

Data mining software of IBM SPSS Modeler 14.2 has been used in the research for modelling neural network and result validation. The data were divided into training and testing data. $70 \%$ of data were training and $30 \%$ of them were testing data. Research stages have been indicated in fig. (4).

\section{Model assessment}

In this stage, output model of training data was used for testing data. In other words, testing data (30\% of data in the research) are predicted by derived model and results of prediction are compared with reality using this model.

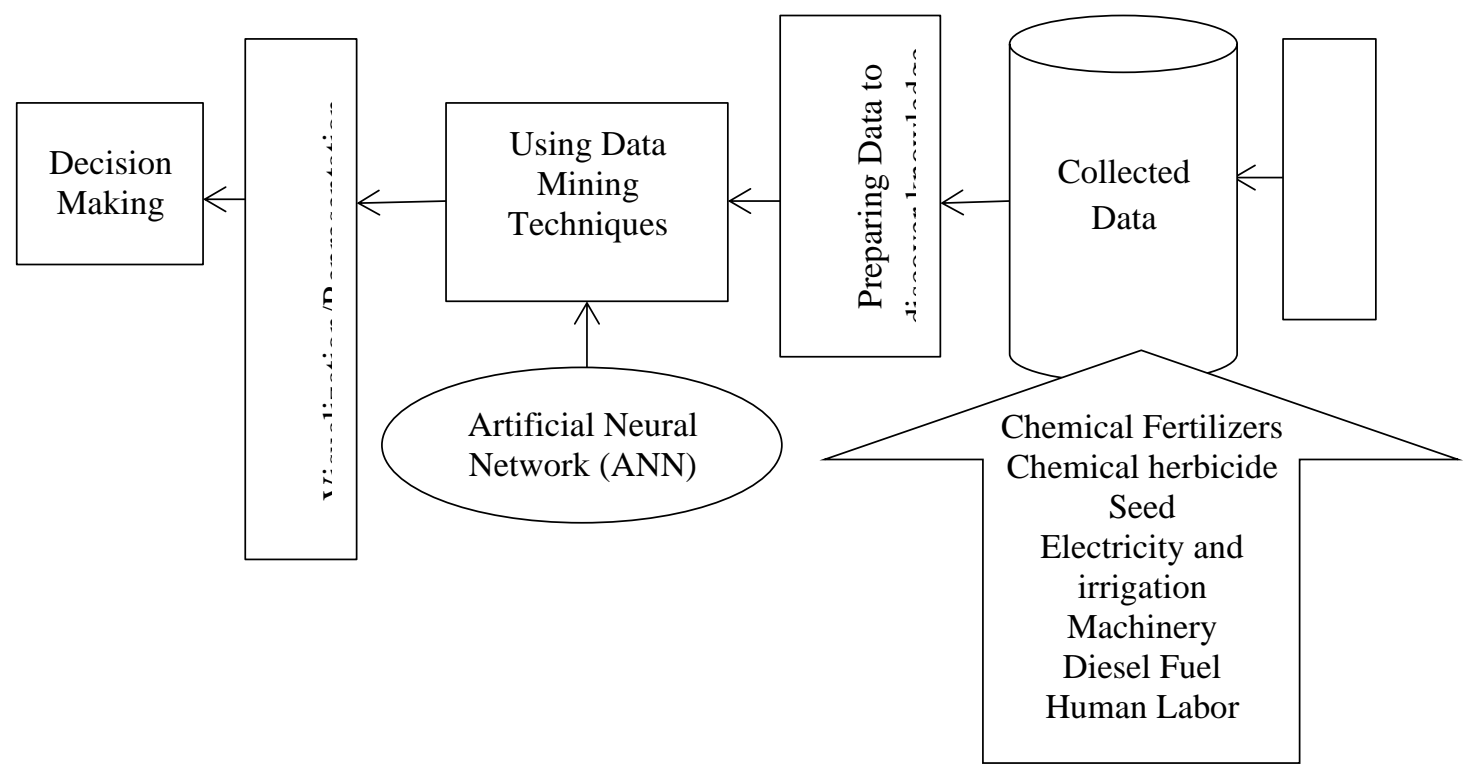

Fig. (4): Proposed framework. 


\section{Results \& Discussion}

Analysis of energy input and output in wheat production

In the first research phase, wheat farms should be studied in order to investigate energy consumed in farms.

\section{Input energies based on inputs consumed in farms}

Table (2) showed input energies in production of wheat farms. As seen in table (2), between consumed inputs, chemical Fertilizers 40723.67 $\mathrm{MJ} \mathrm{ha}^{-1}$ (62.92\%) energy has been determined as the first energy input for production of wheat in farms. On average, total consumed energy in process of wheat production in farms was $64720.53 \mathrm{MJ} \mathrm{ha}^{-1}$ of which $62.92 \%$ associate with inputs of chemical fertilizer. In another study in Iran, reported by Houshyar et al. (2010), total energy input and chemical fertilizer, in wheat farming were $38817.82 \mathrm{MJ} \mathrm{ha}^{-1}$ and 12347.44 $\mathrm{MJ} \mathrm{ha}^{-1}$, respectively. In another study in Iran, Shahin et al. (2008) found that total energy input and chemical fertilizer in wheat production were $38356.39 \mathrm{MJ} \mathrm{ha}^{-1}$ and 14749.51 $\mathrm{MJ} \mathrm{ha}^{-1}$, respectively. In another study in India, Nassiri et al. (2009) noted that total energy input and chemical fertilizer in wheat production were $15261 \mathrm{MJ} \mathrm{ha}^{-1}$ and $8004 \mathrm{MJ} \mathrm{ha}^{-1}$, respectively.

\section{Output energy of wheat farms}

Product yield for farms has been summarized in table (3).

Table (2): Input energy in wheat farms.

\begin{tabular}{ccc}
\hline Input & $\begin{array}{c}\text { Average (MJ ha- } \\
\mathbf{1}^{-}\end{array}$ & $\begin{array}{c}\text { Percent } \\
\mathbf{( \% )}\end{array}$ \\
\hline Human Labor & 2078.03 & 3.21 \\
\hline Diesel Fuel & 9304.44 & 14.38 \\
\hline $\begin{array}{c}\text { Electricity and } \\
\text { irrigation }\end{array}$ & 3741.05 & 5.78 \\
\hline Machinery & 4532.11 & 7.00 \\
\hline Chemical Fertilizers & 40723.67 & 62.92 \\
\hline Chemical herbicide & 2390.42 & 3.69 \\
\hline Seed & 1950.81 & 3.01 \\
\hline Total input energy & 64720.53 & 100 \\
\hline
\end{tabular}

Table (3): Yield of farms.

\begin{tabular}{ccc}
\hline Farm & Yield (ton ha $\left.{ }^{-1}\right)$ & Output energy $\left(\mathrm{MJ} \mathrm{ha}^{-1}\right)$ \\
\hline Wheat & 3.12 & 45864 \\
\hline
\end{tabular}

Product yield has been 3.12 tons of wheat per hectare in farms of Khuzestan province. Concerning degree of harvested wheat and energy of wheat per kilogram, output energy of farms was obtained and it is equal to $45864 \mathrm{MJ}$ $\mathrm{ha}^{-1}$. 


\section{Data mining}

Information used in this research was collected from farms of Khuzestan province. 155 farms (where wheat was produced between 2014 and 2018) were used as database. Executive stage of the second phase of the research (data mining) was divided into six stages of data identification and selection, data description, data pre-processing and preparation, data analysis and modeling, model evaluation and validation and model development.

\section{Stage of data identification and selection}

In the first stage, information available about consuming inputs into process of wheat production has been studied. Concerning collected information, seven effective variables required for modeling energy consumption in process of wheat production were defined and stored in an informational bank of farms as separate fields. These seven variables are independent variables of the research and they are as follows: human labor, diesel fuel, electricity and irrigation, machinery, chemical fertilizers, chemical herbicide and seed. Variable of output energy of the farm is dependent variable of the research.

\section{Data description and definition of variables used in the model}

Among seven input variables in neural network, seven variables were previously defined in energy analysis (the first stage of research).

Data used in this research is entered in IBM SPSS modeler 14.2 in form of an Excel file with 8 columns including seven independent variables (input) and one dependent variable (target) and descriptive information of variables has been shown in table (4). Table (4) includes type of variable, minimum and maximum amounts of the variable, variable mean, standard deviation and number of valid records in database of each variable.

Table (4): Description of all wheat variables used for this study.

\begin{tabular}{lcccccc}
\hline \multicolumn{1}{c}{ Variable } & $\begin{array}{c}\text { Variable } \\
\text { type }\end{array}$ & $\begin{array}{c}\text { minimum } \\
\text { amount }\end{array}$ & $\begin{array}{c}\text { maximum } \\
\text { amount }\end{array}$ & Average & $\begin{array}{c}\text { Standard } \\
\text { deviation }\end{array}$ & $\begin{array}{c}\text { number of } \\
\text { valid } \\
\text { records }\end{array}$ \\
\hline $\begin{array}{l}\text { Chemical } \\
\text { Fertilizers }\end{array}$ & Continuous & 30093.720 & 317759.29 & 40606.37 & 22582.104 & 155 \\
\hline $\begin{array}{l}\text { Electricity and } \\
\text { irrigation }\end{array}$ & Continuous & 3004.32 & 4987.35 & 3586.95 & 339.29 & 155 \\
\hline $\begin{array}{l}\text { Chemical } \\
\text { herbicide }\end{array}$ & Continuous & 1444.38 & 12400.70 & 2289.67 & 863.93 & 155 \\
\hline Seed & Continuous & 2940 & 3675 & 3180.89 & 320.87 & 155 \\
\hline Machinery & Continuous & 1000.76 & 41397.80 & 4283.78 & 3123.98 & 155 \\
\hline Diesel Fuel & Continuous & 6004.65 & 96347.11 & 9254.20 & 7108.81 & 155 \\
\hline Human Labor & Continuous & 1100.28 & 2299.56 & 2045.24 & 272.47 & 155 \\
\hline Output Energy & Continuous & 54235.00 & 64668.00 & 59864.17 & 1701.35 & 155 \\
\hline
\end{tabular}


Stage of data pre-processing and preparation

Before modeling, raw data collected from wheat farms were prepared and pre-processed for improvement of data quality. Data preprocessing and preparation include standardization of unique values in different data sources, correction or deletion of inconsistent and irrational values and addition of different sources based on the number of standardized farm. Also, presence of unconventional records in database increased error factor in results of data mining. Therefore, identification and management of such unconventional data is very important in data preparation stage. Concerning statistical data description, there is no missing data among records in this stage.

\section{Stage of data analysis and modeling}

Data are modelled in this stage and necessary analyses are presented regarding model validation. In order to predict output energy of wheat farms and to enter the software, final database had 1240 records and 8 fields of input and output variables. In order to model data, field of output energy variable was introduced to the software as output and other variables (fields) were introduced to the software as input variables. The main algorithm used in this research for energy of wheat farms is artificial neural network. The network used here is multilayer perceptron which is one of the most practical artificial neural networks. Number of hidden layers of the network is one layer with three neurons (Fig. 5).

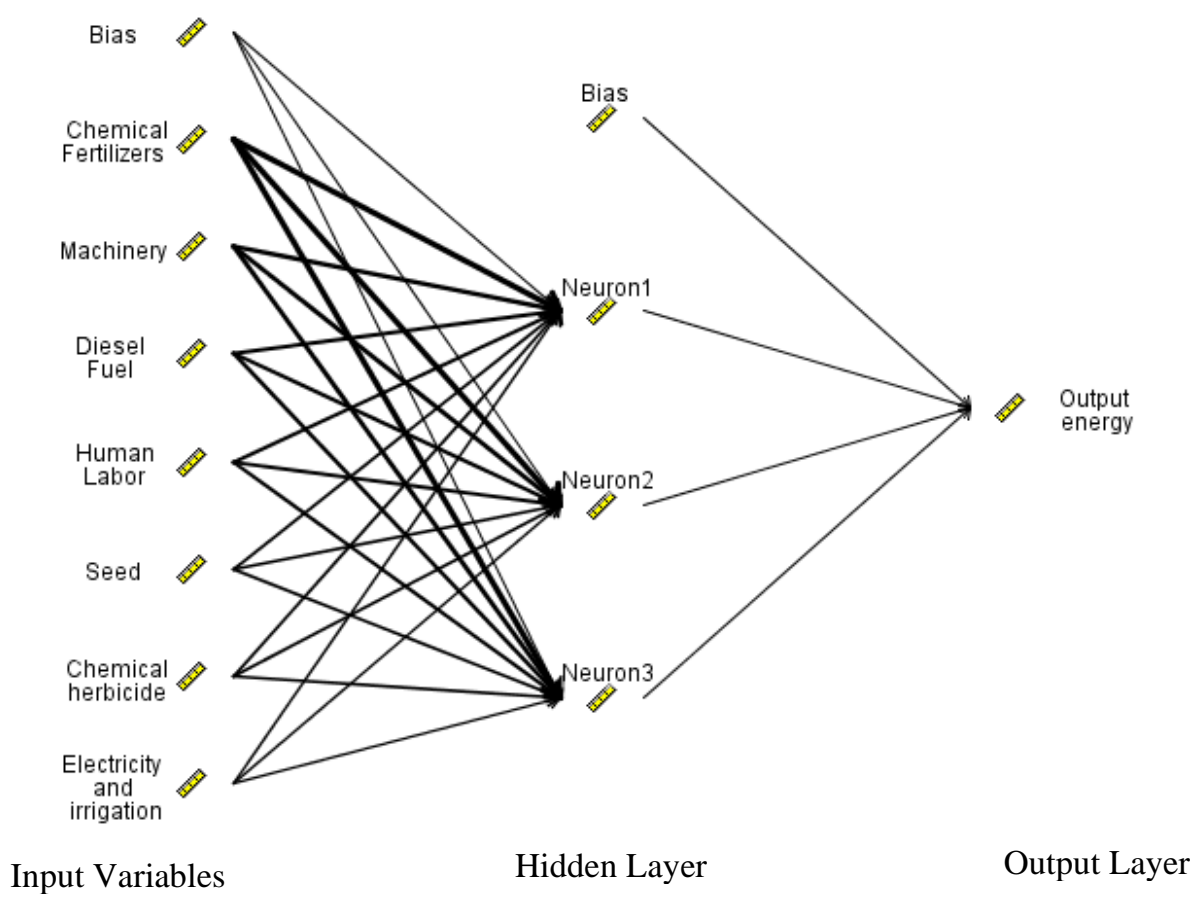

Fig. (5): Architecture of a multilayer perceptron.

The condition for stopping modeling is that if error is not reduced, optimization will be stopped. In present model, data prediction precision was $93.08 \%$. Concerning description of input and output variables, it is noteworthy that some variables are more effective on prediction of the model. In the graph of neural network in fig. (6), descending trend of effect of variables has been determined by target variable. The first variable with the highest 
effect is chemical fertilizers. Concerning Table (5), variables of chemical fertilizers, machinery \& diesel fuel with coefficients of $0.2987,0.2064$ and 0.1527 respectively have the highest effect on output variable (productive energy). Other variables are effective as well but their effectiveness is less than the three variables.

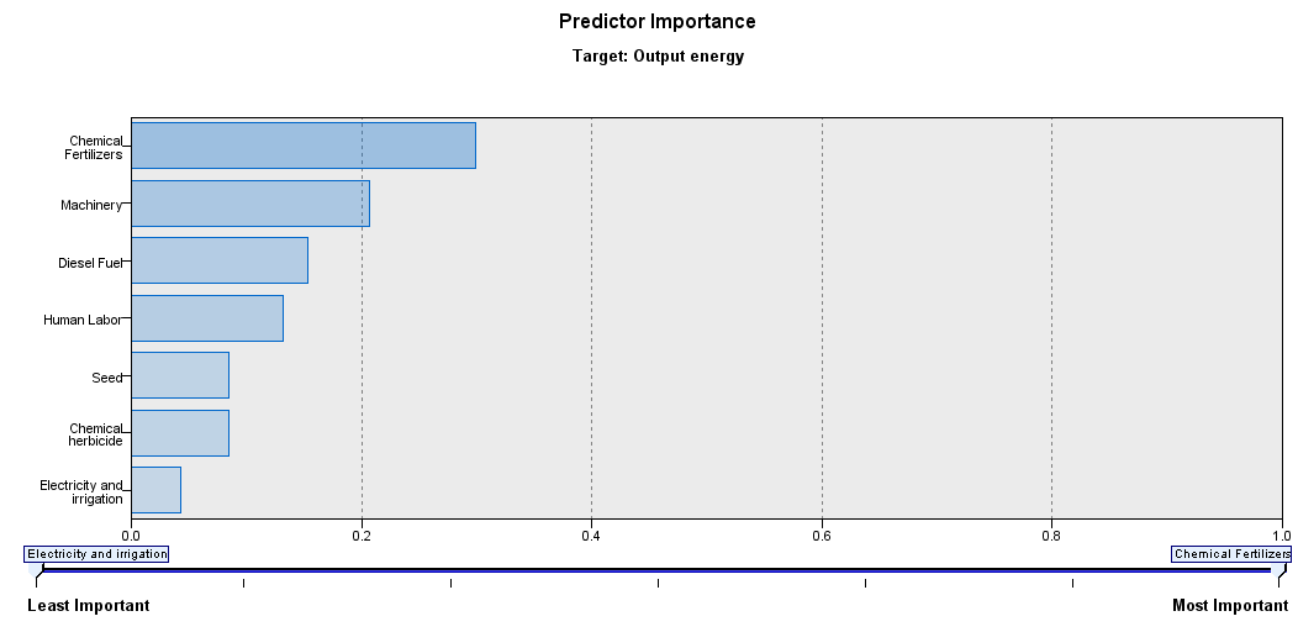

Fig. (6): Predictor importance (Target: output energy)

Table (5): The importance order of variables in prediction of target variable.

\begin{tabular}{lc}
\hline \multicolumn{1}{c}{ Variable } & coefficient \\
\hline Human labor & 0.1315 \\
\hline Seed & 0.0842 \\
\hline Chemical herbicide & 0.0842 \\
\hline Machinery & 0.2064 \\
\hline Electricity and irrigation & 0.0423 \\
\hline Diesel fuel & 0.1527 \\
\hline Chemical fertilizers & 0.2987 \\
\hline
\end{tabular}

\section{Model evaluation and validation}

After preparation of model, it should be evaluated. Evaluation results cause improvement of model and they make it practical. Since the method presented in every research should be measured based on validity and concerning that the research method is data-oriented, validation method is as follows: data are divided into two training and testing data collections. Training data makes the model and testing data evaluates the model. In other words, testing data were predicted by extracted model and prediction results are compared with reality by this model.
Data were divided randomly by software. Regarding number of data in each set, number of training data is always more than testing data. In present research, number of training sets is $70 \%$ (109 farms) and the rest (30\%) has been considered as testing data (46 farms) (Fig. 7). Validity value is tested by results of new data and training data are entered the algorithm as observer and evaluate results of its accuracy. Amount of prediction precision in neural network algorithm meaning the ratio of correct predicted records to total records was $93.08 \%$ (Fig. 8). Therefore, the model made by neural network has high estimative precision. Another argument is how precision of 
prediction methods can be measured. In order to evaluate precision of prediction models (the difference between the real value and predicted value of dependent variable), index of mean absolute value of prediction error is used. Mean absolute error value (MAE) of training data and testing data is 1368.09 and 1650.39 respectively which is an optimal value (Table
6). It is clear that in order to increase precision of a predictive method, the values of above mentioned indices should be small. Also, linear correlation between real and predicted values is 0.92 and $0.88 \%$ for training data and testing data respectively and it suggests a strong correlation.

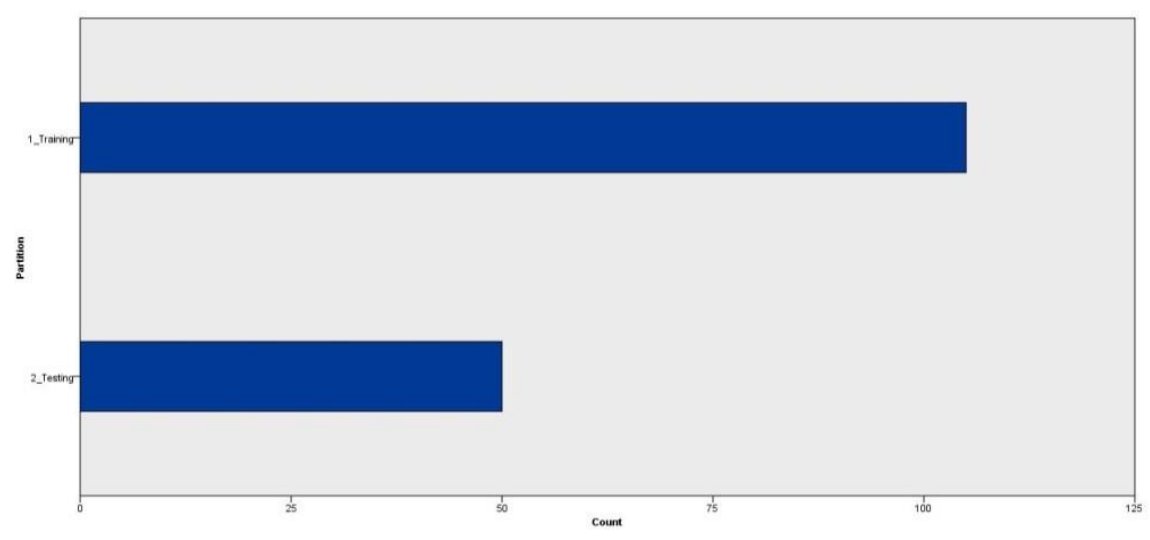

Fig. (7): Ratio of training and testing data in the neural network model.

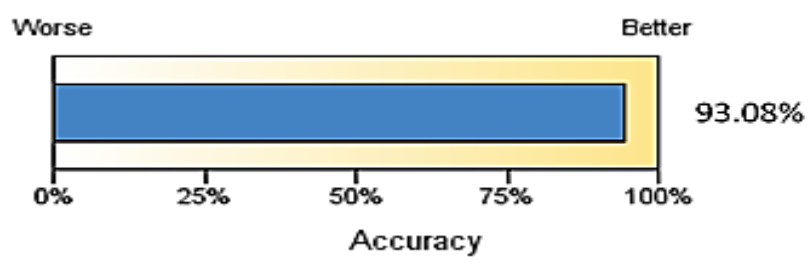

Fig. (8): Amount of predictive precision in neural network algorithm.

Table (6): Comparing predicted output energy with actual output energy.

\begin{tabular}{lcc}
\hline \multicolumn{1}{c}{ Partition } & 1_Training & 2_Testing \\
\hline Minimum Error & -2390.774 & -4870.99 \\
\hline Maximum Error & 3782.924 & 5291.23 \\
\hline Mean Error & 109.245 & 217.730 \\
\hline Mean Absolute Error & 1368.098 & 1650.398 \\
\hline Standard Deviation & 1023.45 & 1458.93 \\
\hline Linear Correlation & 0.923 & 0.885 \\
\hline Occurrences & 109 & 46 \\
\hline
\end{tabular}

\section{Model development}

In this stage, the model and its results can be presented to farmers to be used in future for prediction of energy production during the process of wheat production. Therefore, after necessary reports, it was explained the most effective variables on prediction of output 
energy of wheat farms based on this model. Concerning that variables of chemical fertilizers, machinery \& diesel fuel are the most effective variables on output energy of wheat farms, energy efficiency will be increased in farms if input variables are optimized.

\section{Conclusion}

Data of wheat farms of Khuzestan province was used in present study. In the first research phase, input and output energies of farms were analyzed. In the second research phase (data mining), database was divided into training and testing parts. Then, a model was created based on artificial neural network technique of data mining in order to estimate energy in process of wheat production using IBM modeler 14.2 and training dataset. As a result, the model was assessed using testing datasets and could reach $93.08 \%$ precision for estimation of output energy. It is clearly evident that this model has a good accuracy for estimation of amounts of output energy. Also, results of the study indicate that prediction methods provide proper source allocation and increase efficiency of inputs by presenting more accurate picture of energy status in wheat farms. It is suggested to use other techniques available for data mining in future studies and they are compared with results of the present research, exploration of rules for including input and output variables in database via farma can help considerably data mining in order to extract more real results from them. Concerning high potential of data storage and advanced analysis in wheat farms, it is suggested to collect systematically and mechanize data by creating proper software infrastructures, data warehouse with aim of using reporting and analytic tools. Finally, concerning that data of this research belongs to one province, it is suggested that a similar research is conducted on other provinces and results are compared with results of the present research and other methods.

\section{Acknowledgement}

This paper was supported by Shahid Chamran university of Ahvaz, Iran.

Conflict of interest: The authors declare that they have no conflict of interest.

\section{ORCID:}

\section{N. Monjezi: 0000000182297706}

\section{References}

Almaliki, S., Alimardani, R., \& Omid, M. (2016). Artificial neural network based modeling of tractor performance at different field conditions. Agricultural Engineering International: CIGR Journal, $\quad 18, \quad 262-274$. https://cigrjournal.org/index.php/Ejounral/article/vi ew/3880

Almaliki, S. (2017). Development and evaluation of models for MF-285 tractor performance parameters using computational intelligence Techniques. $\mathrm{Ph}$. D. Thesis. University of Tehran, 215pp.

Ayman, E.K.; Kadry, M., \& Walid, G. (2015). Proposed framework for implementing data mining techniques to enhance decisions in agriculture sector. Procedia Computer Science, 65, 633-642. https://doi.org/10.1016/j.procs.2015.09.007

Banaeian, N., \& Zangeneh, M. (2011). Modeling energy flow and economic analysis for walnut production in Iran. Research Journal of Applied Sciences, Engineering and Technology, 3, 194201.https://www.researchgate.net/publication/2683 41453

Beheshti Tabar, I., Keyhani, A., \& Rafiee, S. (2010). Energy balance in Iran's agronomy (1990-2006). Renewable and Sustainable Energy Reviews, 14, 849-55. https://doi.org/10.1016/j.rser.2009.10.024

Chapman, P., Clinton, J., Kerber, R., Khabaza, T., Reinartz, T., Shearer, C., \& Wirth, R. (2011). CRISP-DM 1.0: Step-by-step data mining guide. Viewed 22 October 2011.http://www.crispdm.org/CRISPwP-0800.pdf;

Efendigil, T., Onut, S., \& Kahraman, C. (2009). A decision support system for demand forecasting with artificial neural networks and neuro-fuzzy models: A 


\section{Monjezi N /Basrah J. Agric. Sci., 34(1): 14-27, 2021}

comparative analysis. Expert Systems With Applications, $\quad 36, \quad 6697-6707$. https://doi.org/10.1016/j.eswa.2008.08.058

Ekasingh, B., Ngamsomsuke, K., Letcher, R., \& Spate, J. (2005). A data mining approach to simulating farmers' crop choices for integrated water resources management. Journal of Environmental Management, $\quad 77, \quad 315-325$. https://doi.org/10.1016/j.jenvman.2005.06.015

Everinghama, Y. L., Smyth, C. W., \& Inman-Bamber, N. G. (2009). Ensemble data mining approaches to forecast regional sugarcane crop production. Agricultural and Forest Meteorology, 149: 689-696. https://doi.org/10.1016/j.agrformet.2008.10.018

Fernandes, J. L., Rocha, J. V., \& Lamparelli, R. A. C. (2011). Sugarcane yield estimates using time series analysis of spot vegetation images. Scientia Agricola, $\quad 68, \quad$ 139-146. https://doi.org/10.1590/S0103-90162011000200002

Ferraro, D. O., Rivero, D. E., \& Ghersa, C. M. (2009). An analysis of the factors that influence sugarcane yield in Northern Argentina using classification and regression trees. Field Crops Research, 112, 149157. https://doi.org/10.1016/j.fcr.2009.02.014

Geetha, M. C. S. (2015). A Survey on data mining techniques in Agriculture. International Journal of Innovative Research in Computer and Communication Engineering, 3, 887-892. https://link.springer.com/article/10.1007/s12351009-0054-6

Goktepe, A. B., Altun, S., \& Sezar, A. (2005). Soil clustering by fuzzy C-Means algorithm. Advances in Engineering Software, 36, 691-698. https://doi.org/10.1016/j.advengsoft.2005.01.008

Houshyar, E., Sheikh Davoodi, M. J., \& Nassiri, S. M. (2010). Energy efficiency for wheat production using data envelopment analysis (DEA) technique. Journal of Agricultural Technology, 6, 663-672. https://www.researchgate.net/publication/23565457 1

Jeysenthil, K. M. S., Manikandan, T., \& Murali, E. (2014). Third generation agricultural support system development using data mining. International Journal of Innovative Research in Science, Engineering, 3, 9923-9930. http://www.ijirset.com/upload/2014/march/6_Third. pdf

Kalpana, R., Shanthi, N., \& Arumugam, S. (2014). A survey on data mining techniques in agriculture.
International Journal of Advanced Computer Science and Technology, 3, 426-431. http://warse.org/pdfs/2014/ijacst05382014.pdf

Kaltschmitt, M., Reinhardt, G. A., \& Stelzer, T. (1997). Life cycle analysis of befouls under different environmental aspects. Biomass. Bioenergy, 12, 121-134. https://doi.org/10.1002/ese3.315

Khan, M. A., Zafar, J., \& Bakhash, A. (2008). Energy requirement and economic analysis of sugarcane production in Dera Islamic Khan district of Pakistan. Gomal University Journal of Research, 24, 72-82. https://www.researchgate.net/publication/26204815 6

Khedr, A. E., Kadry, M., \& Walid, G. (2015). Proposed framework for implementing data mining techniques to enhance decisions in agriculture sector applied case on food security information center ministry of agriculture, Egypt. Procedia Computer Science, 65, 633-642.

https://doi.org/10.1016/j.procs.2015.09.007

Khoshnevisan, B., Rafiee, S., Omid, M., Mousazadeh, H., \& Sefeedpari, P. (2013). Prognostication of environmental indices in potato production using artificial neural networks. Journal of Cleaner Production, 5, 402-409. https://doi.org/10.1016/j.jclepro.2013.03.028

Kitani, O. (1999). Energy and Biomass Engineering. In: CIGR Handbook of Agricultural Engineering Vol. 5, ASAE Publication, St. Joseph, M. I., 330pp. http://cigr.org/documents/CIGRHandbookVol5.pdf

Liao, S., \& Wen, C. (2007). Artificial neural networks classification and clustering of methodologies and applications- literature analysis from 1995 to 2005. Expert Systems With Applications, 32, 1-11. https://doi.org/ 10.1016/j.eswa.2005.11.014

Mandal, K. G., Saha, K. P., Ghosh, P. K., Hati, K. M., \& Bandyopadhyay, K. K. (2002). Bioenergy and economic analysis of soybean-based crop production systems in central India. Biomass. Bioenergy, 23, 337-345. https://doi.org/10.1016/S0961-9534(02)00058-2

Medar, R. A., \& Rajpurohit, V. S. (2014). A survey on data mining techniques for crop yield prediction. International Journal of Advance Research in Computer Science and Management Studies, 2, 5964. https://www.academia.edu/9421293

Mousavi-Avval, S. H., Rafiee, S., Jafari, A., \& Mohammadi, A. (2011). Optimization of energy 


\section{Monjezi N /Basrah J. Agric. Sci., 34(1): 14-27, 2021}

consumption for soybean production using Data Envelopment Analysis (DEA) approach. Applied Energy, $\quad$ 88, 3765-3772. https://doi.org/10.1016/j.apenergy.2011.04.021

Mucherino, A., Papajorgji, P., \& Pardalos, P. M. (2009). A survey of data mining techniques applied to agriculture. Operational Research, 9, 121-140. https://doi.org/ 10.1007/s12351-009-0054-6

Nassiri, S. M., \& Singh, S. (2009). Non-parametric energy use efficiency, energy ratio and specific energy for irrigated wheat crop production. Iran Agricultural Research, 28, 27-38. http://iar.shirazu.ac.ir/article_151_3e06dddfdf6ccfd feb5f9b2aaca5c75d.pdf

Oliveira, M. P. G., Bocca, F. F., \& Rodrigues, L. H. A. (2017). From spreadsheets to sugar content modeling: A data mining approach. Computers and Electronics in Agriculture, 132, 14-20. https://doi.org/10.1016/j.compag.2016.11.012

Phillips-Wren, G., Sharkey, P. H., \& MorssDy, S. (2008). Mining lung cancer patient data to assess healthcare resource utilization. Expert Systems With Applications, 35 , 1611-1619. https://doi.org/10.1016/j.eswa.2007.08.076

Ramesh, D., \& Vardhan, B. V. (2013). Data mining techniques and applications to agricultural yield data. Journal of Advanced Research in Computer and Communication Engineering, 2, 3477-3480. https://www.ijarcce.com/upload/2013/september/31 -h-dantam\%20ramesh\%20-

data $\% 20$ mining $\% 20$ techniques $\% 20$ and $\% 20$ applicat ion\%20to.pdf

Raorane, A.A. \& Kulkarni, R.V. (2013). Review- role of data mining in agriculture. International Journal of
Computer Science and Information Technology, 4, 270 http://cloud.politala.ac.id/politala/1.\%20Jurusan/Te knik\%20Informatika/19.\%20ejournal/Jurnal\%20Internasional\%20TI/IJCSIT/Vol \%204/ISSUE\%202/ijcsit20130402018.pdf

Raorane, A. A., \& Kulkarni, R. V. (2015). Application of data mining tool to crop management system. Russian Journal of Agricultural and SocioEconomic Sciences, 37, 3-16. https://ideas.repec.org/a/scn/031261/16082009.html

Shahin, S., Jafari, A., Mobli, H., Rafiee, S., \& Karimi, M. (2008). Effect of farm size on energy ratio for wheat production: A case study from Ardabil Province of Iran. American-Eurasian Journal of Agricultural and Environmental Sciences, 3, 604608.

https://www.researchgate.net/publication/23733415 4

Sharma, A. (2006). Spatial data mining for drought monitoring: An approach using temporal NDVI and rainfall relationship. M. Sc. Thesis. Geo-information Science Earth Observation, University of Twente, 75pp. https://www.iirs.gov.in/node/254

Srivastava, A. K., Goering, C. E., \& Rohrbach, R. P. (1993). Engineering Principles of Agricultural Machines. ASAE Publication, 604pp. https://www.amazon.com/Engineering-PrinciplesAgricultural-Machines-2nd/dp/1892769506

Thomas, E. (2017). An artificial neural network for realtime hardwood lumber grading. Computers and Electronics in Agriculture, 132, 71-75. https://doi.org/10.1016/j.compag.2016.11.018 
Monjezi N /Basrah J. Agric. Sci., 34(1): 14-27, 2021

\section{تتبؤات الطاقة لإنتاج القمح باستخدام تقتية استخراج البيانات في إيران \\ نسيم منجزي \\ قسم هندسة النظم الحيوية، كلية الزر اعة، جامعة شهيد جمران، الأهو از ، إيران}

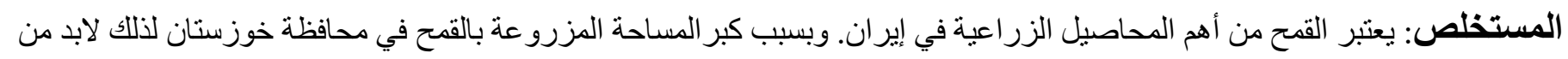

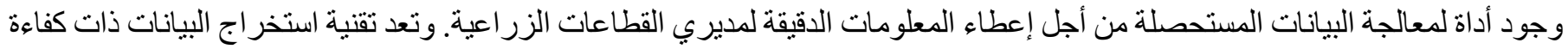

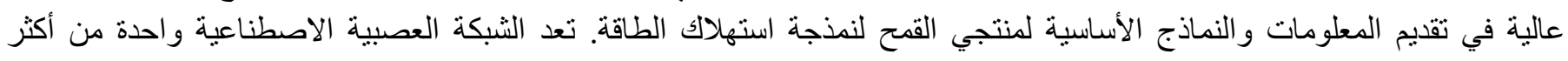

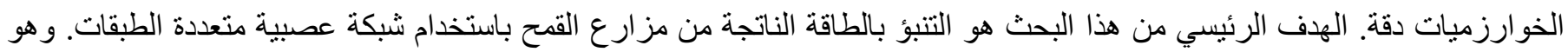

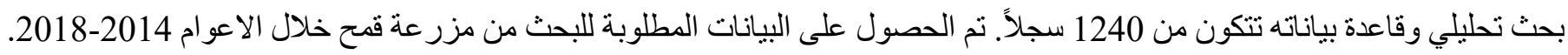

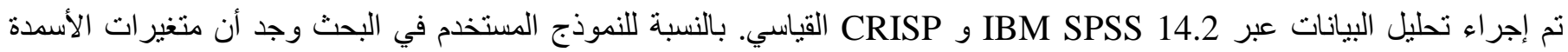
الكيماوية والآلات ووقود الديزل ذاتئ الات المعاملات

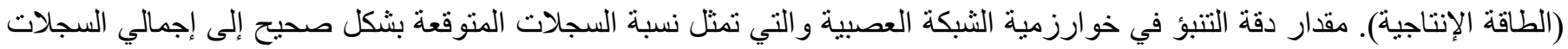

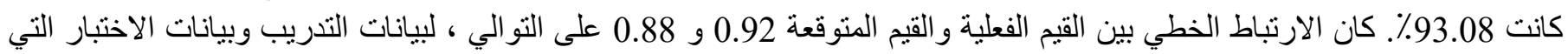

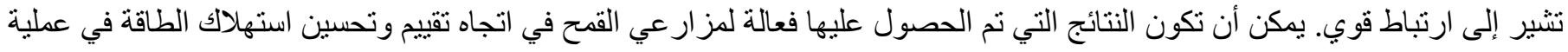
إنتاج القمح وتقليل استهلاك مدخلات الطاقة. الكلمات المفتاحية: الطاقة، التتبؤ، التتقيب في البيانات، ANN، القمح. 